\title{
Understanding Metaphors and their Translation from the Linguistic and Cognitive linguistics perspectives.
}

\author{
Megaptche Megaptche Yvan Rudhel \\ 2929185561@qq.com \\ Southwest University, Chongqing,40715, China
}

\begin{abstract}
The paper explores the different approaches to metaphor understanding and metaphor translation within the fields linguistics and cognitive linguistics. Semantics scholars view metaphors as "the application of an alien name by transfer either from genus to species, or from species to species, or by analogy"(Aristotle), while pragmatics scholars view metaphor as being dependent on context. Scholars of the cognitive linguistics school (Lakoff \& Johnson, 1980; Lakoff, 1987) portray metaphor as a system used to comprehend one conceptual domain in terms of another conceptual domain via sets of correspondences between these two domains. This paper focuses on the main approaches to metaphors understanding, and approaches to metaphor transfer and translation, as metaphor translation represents a burden for translators no matter the language. This is due to the fact that translation involves multiple processes that include both linguistic and non-linguistic elements. Based on linguistics and cognitive linguistics theories, a number approaches and procedures such as prescriptive approach, the descriptive approach and the cognitive approach have been developed by scholars for the translation of metaphorical expressions.
\end{abstract}

Keywords: metaphor; translation; metaphor translation; cognitive linguistics; Conceptual Metaphor Theory.

\section{Introduction}

Due to the complexity of metaphors, it has always been difficult to understand them, therefore it becomes difficult to translate them as well. Metaphors are viewed by linguists from different perspectives, which constitute different schools of thought. For some scholars, metaphor is a mere figure of speech which is used to embelish the language it is used in. This is the case for scholars who have limited metaphor study within the area of semantics (Aristotle, Max Black, etc) and pragmatics (Paul Grice, Searle, Sperber \& Wilson). According to the cognitive linguistics scholars, a metaphor cannot be considered as a mere figure of speech as 
it is embodied to human nature. In other words, as George Lakoff and Mark Johnson point out, we cannot live without metaphor. Therefore, metaphor is grounded within a given culture and it cannot be translated without a perfect understanding of the soutce and target culture.

The study of metaphor translation within the field of Translation Studies has for has for years been considering metaphor as a translation problem, because the translation of metaphors is relatively difficult exercise. This is the reason why there has always been a debate on the dichotomy translability/untranslability of metaphors. Scholars have attempted to propose some approaches to metaphors translation. Some kept it within the field of linguistics with the prescriptive and descriptive approach while other have studied it as a cognitive linguistics phenomenon.

The present work attempts to bring to light the different theories or approaches to the understanding of metaphors and their translation as well, based on the review of emperical researches in metaphors and metaphors translation.

\section{Metaphors}

The huge the number of researches in order to understand metaphor have brought more questions than answers and scholars never succeeded to provide us with a theory that can be considered as universal. However, their works have brought to the light different schools of thought: semantic metaphors, pragmatic metaphors and cognitive metaphors, etc.

\subsection{Semantic approaches of metaphors}

The semantic approaches of metaphors, explore metaphors from two main views. The Comparison View and the Interaction View. The Comparison View says that metaphor constitutes of an analogical association between two concepts, showing the ressemblance that exist within both ends of the comparison.

The Comparison View goes as far as Aristotle. His views on metaphor had an influence or have at least paralled the classic and contemporary studies of metaphor. According to Aristotle, metaphor is "the application of an alien name by transfer either from genus to species, or from species to species, or by analogy". Aristotle's definition is based on view that a metaphor serve as substitution used to embelish and make suitable the literal language. For the substitution to be successful, there must be a similarity both between the literal expression and the metaphor. The similarity acts as the vehicle that enable the transfer of the message and the meaning of an utterance from one language to the other. My memory is a little foggy is 
undoubtedly a metaphor because, obviously, the fog happens out of the body and not inside the brain. My memory is foggy could be said as, 'my memory is obscured in the same way that fog sometimes obscures my view'.

The comparison View lasted until Ivor Armstrong Richards introduced the Interaction View. Richards created the notions of tenor (or topic) and vehicle and focused on the relationship that lies between them. This is what Richards says about metaphor:

In the simplest formulation, when we use a metaphor we have two thoughts of different things active together and supported by a single word, or phrase, whose meaning is a resultant of their interaction. (Richards, 1936: 93 as cited in Schmidt, 2012: 31)

Basically, the form in which the concept is expressed is called the vehicle, whereas the concept which one tries to express in the tenor or the topic. For instance, in the above example, the memory difficulty is used as the tenor which is what is described and the vehicle which is the way it is expressed is 'foggy'. Richards introduced the concept of tension in order to show the reason why some metaphors are hard to decipher than others. This concept is grounded in the idea that, there should be a huge difference between the tenor and the vehicle to have a greater tension. Thus, there is more tension in Shakespeare's Juliet is the sun than there is in My memory is foggy because, as far as this theory is concerned, in Juliet is the sun there are quite no similarities between 'Juliet' and 'sun' than between 'memory' and 'fog'.

Though Max Black has worked on the Substitution and Comparison views of metaphors, his preferred view is the Interaction View of metaphor, because the first two see metaphor as a device used only for stylistic and the Interaction View gives more perspectives. He suggested that what lies between the vehicle and the tenor was an unrevealed "analogy or similarity in the form of a thick or elliptical simile" (274). Black opposes Aristotle's view as he suggests that a metaphor cannot be used only for decorative purposes.

The problem of the semantic theories of metaphor is the majority of its proponents see metaphor as a way of extending language, wihich implies that the same thing can be said in several ways and that except from the choice of words, the litera language and metaphor are not different. The semantic theories forgets some of the aspects that make metaphors impossible to be changed with literal knowledge. In other words, the semantic approach to metaphor is unabl e to provide assistance for metphor translation and translation assessment.

\subsection{Metaphors and pragmatics}

As they are opposed to Roman Davidson, 1968 who states that "metaphors are their meanings and nothing more", pragmatics sholars put emphasis on the gap that exists between the meaning of a metaphor and its linguistic form it is expressed.

The theory of 'Indirect Speech Acts' goes as far as Austin in his How to Do Things In Words (1975)(cf 
Goran Schmidt, 2012). This theory utterances can be neither restricted to what is directly said in the sentence nor to the utterance truth or falsity.

For Searle, pragmatics analysis are based on how the language is used in order to transmit what the speaker intends and also the relationship between the speaker and the utterance. In such conditions, metaphor cannot be simply considered as literal expression, for an abtract or concrete part of the later will be lost. Metaphor represents the difference between what is said and what was intended. As a result, in order to understand the message conveyed, the receiver must follow a couple of rules. For instance, at a funeral a man/woman utters "she kicked the bucket" referring to a corpse in the casket, but while milking a cow, on another occasion, the same man/woman utters, "she kicked the bucket", in reference to someone, the receiver will not understand the same utterance the same, because the the contexts are clearly different.

Such a difference is caused by factors which external to the utterancewhich are elaborated in Paul Grice's theory of 'Conversational Implicatures', that is grounded on the speaker-listener relationship as to join or at least reduce the gap that exist between the semantic meaning and the contextual meaning and determine the the speaker and the listener's roles.

Table 1. Paul Grice's theory of 'Conversational Implicatures'.

\begin{tabular}{|c|c|c|c|c|}
\hline Co-operative principle & Quantity maxims & Quality maxims & $\begin{array}{c}\text { Maxim of } \\
\text { relation }\end{array}$ & Manner maxims \\
\hline $\begin{array}{l}\text { Your contribution must be } \\
\text { made such as required, } \\
\text { following the purpose or } \\
\text { the direction of the } \\
\text { conversation you are } \\
\text { involved in. }\end{array}$ & $\begin{array}{l}\text { 1. Your contribution must } \\
\text { be as informative as } \\
\text { required by the current } \\
\text { purpose of the } \\
\text { coversation. } \\
2 \text {. Your contribution must } \\
\text { not be more informative } \\
\text { that what is required. }\end{array}$ & $\begin{array}{l}\text { Supermaxim: your } \\
\text { contribution must be } \\
\text { true. } \\
\text { 1. You must say } \\
\text { things you believe to } \\
\text { be false. } \\
2 \text {.You must say things } \\
\text { you have evidence of. }\end{array}$ & Be relevant & $\begin{array}{l}\text { Supermaxim: Be perspicuous. } \\
\text { 1. Do not fall in obcurity of } \\
\text { expression. } \\
\text { 2. Avoid ambiguity. } \\
\text { 3. Be brief (avoid unnecessary } \\
\text { proxility). } \\
\text { 4. Be orderly }\end{array}$ \\
\hline
\end{tabular}

Sperber and Wilson, 1986:243 are not buying the views of the Speech Acts theory and they argue that it deals with a "vast range of data that (...) is of no special interest to pragmatics.". As an alternative, they introduce the concept of 'propositional attitudes' which gave birth to the Relevance Theory. To make this new theory effective, its proponents try to show that 'human cognition is likely to be geared to maximizing relevance' and 'every act of overt communication conveys a presimption of its own optimal relevance' (Sperber \& Wilson 260). It is according to the information they think relevant to the message that hearers will recat to an encoded message. The difference with Grice's theory of 'Conversational Implicatures', is that the Relevance 
Theory described by Sperber and Wilson deals cognitive effects and processing efforts.

The pragmatic approaches to metaphor understanding are not putting asside the semantic theories of metaphor understanding, but rather, they seek to explain that meaning has to go along with a pragmatic support which is the most most important. The pragmatic views are also seeking to show that a metaphor is not just used to embellish the language nor an another way of saying what has been said literally. Thus pragmatics enable a larger view of metaphor in which the metaphor is seen as part of the speech act, as an element similar to intonation, connotation, image and context (Kerbrat-Orecchioni 70).

\subsection{Conceptual Metaphor Theories}

In this section, I focuses on the review the contributions of scholars such as Lakoff \& Johnson, 1980; 1987, Kövecses, 2002 for metaphor from the perspective of cognitive linguistics and more precisely that of Conceptual Metaphor Theory (CMT). Until the 90's proponents of linguistics and cognitive science were defining metaphor as a linguitic tool (as seen above ) without no other fundamental significance for cognition as whole. Recent researches, however, have proposed a completely different approach to metaphor understanding which sees it as as a way of thinking and as the foundation of all abstract thought. This view ws inroduced by George Lakoff and Mark Johnson in their book Metaphors We Live By. Lakoff and Johnson's aim was to change the presumption that metaphor is a linguistic device and by providing systematic evidence, promote metaphor as fundamental aspect of thought. In addition, they say that it is actually because metaphors are based on recurring patterns of embodied experience that they work.

\subsubsection{Systematicity of Conceptual Metaphors}

Lakoff and Johnson argue that metaphorical concepts constitute a system. This is illustrated with the concept ARGUMENT and the conceptual metaphor ARGUMENT IS WAR. The metaphorical expressions below fall in this conceptual metaphor:

Your claims are indefensible;

He attacked every weak point in my argument;

they have reached to the conclusion that we do not always consider arguments war, but word and the expression choice during an argument are in part structures by the concept war. (It is possible to win or lose arguments, those we are having the argument with are our opponents, we attack the opponents points of view and defend ours, etc.Therefore, the conceptual metaphor ARGUMENT IS WAR is a metaphor we live by, as it 
actions performed during an argument are structured by it. The narrow definition Lakoff and Johnson give to metaphor is : "The essence of metaphor is understanding and experiencing one kind of thing in terms of another" (Lakoff \& Johnson, 1980: 5). It is obvious that war and argument are two separated concepts, but ARGUMENT seems to be built, performed, understood, and talked about in reference to WAR. It is worth stressing that according to CMT, far from being limited to language, metaphor is embodied. Thus ARGUMENT IS WAR does not just act as a metaphor, but as metaphorical concept as well. As we partially conceptualize arguments in terms of war, it has a systematic influence on the shape of arguments and on the our attitude during the argument.

For Kövecses, 2002: 4ff, the area of cognitive linguistic defines metaphor as understanding one conceptual doamin in terms of another conceptual domain. This definition can be summarized as follow: CONCEPTUAL DOMAIN (A) IS CONCEPTUAL DOMAIN (B), which corresponds to a conceptual metaphor. The two conceptual domains contained in the conceptual metaphor have specific names. The conceptual domain that is used to understand the other conceptual domain is called the source domain, whereas the conceptual domain which is understood is known as the target domain. For instance, concerning the conceptual metaphor ARGUMENT IS WAR, ARGUMENT is the target domain, while WAR is the source domain. For cognitive linguistics scholars, the way we talk is an extension of our thoughts. Due to the fact that in our languages metaphorical expressions systematically go along with metaphorical concepts, metaphorical expressions can be used to study the nature of a metaphorical concept to understand our activities can be perceived metaphorically. (Lakoff \& Johnson, 1980: 456). Still in attempting to show the systematicity of metaphorical concepts and language as well, Lakoff and Johnson use the conceptual metaphor TIME IS MONEY as an illustration. This metaphor can be found in following expressions:

You are wasting your time;

You don't use your time profitably;

(Lakoff \& Johnson, 1980: 460)

In the modern societies, the time is perceived as valuable commodity, a limited resource, and money as well. Futhermore, the conceptual metaphors TIME IS MONEY, TIME IS A RESOURCE and TIME IS A VALUABLE COMMODITY constitute a system that lies on subcategories, for in the modern days, time is a limited resource and limited resources are valuable, since in the modern socities, time is a resource that is limited, and limited resources are valuable. In the following diagram, Lakoff and Johnson materialize that relationship: 
MONEY

is

A

is

A VALUABLE COMMODITY
TIME IS MONEY

entails

TIME IS A LIMITED RESOURCE

entails

TIME IS A VALUABLE COMMODITY

The subcategorization relationship in their diagram is what they called the 'entailment relationship' existing between metaphors. TIME IS MONEY entails that TIME IS A RESOURCE which entails that TIME IS VALUABLE COMMODITY.

\subsubsection{Types of Conceptual Metaphors}

In order to find out what is involved in the metaphorical structuring of a concept, it is important to identify the basic domains of conceptual structure. There are many types of metaphors. Depending on their cognitive function, metaphors can be classify as follows: ontological, structural and orientational metaphors. (Kövecses,2002: 33).

\section{- Ontological metaphors}

These metaphors also called 'physical' metaphors, because they give an ontoligical status to general categories of abstract target concepts. Examples of ontological metaphors could be:

My fear of insects is driving my wife crazy. (referring)

You've got too much hostility in you. (quantifying)

(Lakoff \& Johnson ,1980)

- Structural metaphors

Said to be the biggest metaphor group, this type of metaphor involves the use of a concept of one domain to structure a concept in another domain. An example of this is where the concept WAR structures ARGUMENT.

He attacked every weak point in my argument.

If you use that strategy, I will wipe you out.

(ibid)

- Orientaional metaphors

They are known as metaphoric patterns in which a concept is shown as possesing a spatial orientaion. They reason why they are called orientational is because the majority is made of orientational patterns such as: updown, in-out, front-back, center-periphery etc. Unlike structural metaphors, this type of metaphor do not 
structure one domain in terms of another, instead they build a system of concepts on its own with respect to one another. (Lakoff \& Johnson 1980:461). The following are examples of orientational metaphors:

(1) CONSCIOUS IS UP; UNCONSCIOUS IS DOWN

Wake up.

He sank down into coma.

(2) HAPPY IS UP; SAD IS DOWN

I'm feeling up

I fell into depression

(Lakoff \& Johnson)

\section{Metaphor Translation}

This section deals with the literature on metaphor translation. Although for centuries metaphor has been considered as a problem in translation studies, it has still been neglected in translation studies for a long time and its literature has remain scarce. However, some scholars have attempted to give relevant contributions. As Kurth (1995: 106ff) mentions, it is only with the interest of the linguits in metaphor, mostly with the upraising of cognitive linguistics and text semantics that translation studies put a particular interest in metaphor.

\subsection{Linguistic approaches of metaphor translation}

\subsubsection{Prescriptive approach}

One of the first proponents of the prespriptive approach to metaphor translation is Peter Newmark. Newmark's model of metaphor translation can also be described as a kind of 'literal pragmatism'. His contribution is said to be prescriptive and pragmatic because he put more emphasis on the pragmatic function of metaphor which he considers as "the most powerful pragmatic factor in translation" (Newmark 1988b: 135). Furthermore, Newmark makes use of a literal approach, as literal translation is dominant in the solutions he prescribed to address metaphor translation issues. According to him, metaphor mainly made of aesthetic and cognitive functions (cf. Newmark, 1988a: 104). The cognitive function of a metaphor comes from the ability is has to add sense to the sign, whereas is aesthetic function comes from the ability it has convey meaning. The message or the pragmatic function of the utterance represent the meaning. Newmark has divided metaphors into six different kinds taking into account their function. 
Table 2. Newmark's typology of metaphors.

\begin{tabular}{|c|c|c|}
\hline Metaphors & Definitions & Examples \\
\hline Dead metaphors & $\begin{array}{l}\text { used subconciously, are apparently not } \\
\text { metaphoric, but have become a part of our } \\
\text { lexicon since they have been overused. }\end{array}$ & Face of the mountain; the foot the table; \\
\hline Cliché metaphors & $\begin{array}{l}\text { These are well known fixed expressions with } \\
\text { metaphoric associations which are only used } \\
\text { replace information of "clear thought". }\end{array}$ & Long time no see; a transparent lie; \\
\hline Stock metaphors & $\begin{array}{l}\text { They are used to describe daily activities or } \\
\text { situations in informal contexts. }\end{array}$ & She can see the fear in eyes. \\
\hline Adapted metaphors & $\begin{array}{l}\text { They are stock metaphors that have been } \\
\text { adapted differently as in proverbs. }\end{array}$ & get them in the door \\
\hline Recent metaphors & $\begin{array}{l}\text { stand for new words that appear metaphorical } \\
\text { used by during a particular period or by } \\
\text { certain persons and whose use has become } \\
\text { common recently. }\end{array}$ & groovy, Skint. \\
\hline Original metaphors & $\begin{array}{l}\text { They are new metaphors found in texts such } \\
\text { as poetry and novel. }\end{array}$ & a forest of fingers. \\
\hline
\end{tabular}

After his typology of metaphors, Newmark proposed seven procedures for metaphor translation, they can be listed as follows:

1. Reproduce of the same image in the TL;

2. Replace the image in the SL a standard TL image provided that it is in acccordance with the TL's culture;

3. Translate the metaphor by a similie, retaining the image;

4. Translate the metaphor by a similie plus sense;

5. Convert the metaphor into sense;

6. Delete the metaphor in it is case redundant;

7.Combine the metaphor with sense.

Following Newmark's approach, James Dickins, 2002; 2005 built his own approach of metaphor translation. In his paper titled "Two models for metaphor translation" (2005), James Dickins deals with issues related to textual analysis and metaphor translation. He puts more emphaisis on Newmark's (1988) metaphor typology and introduce new types of metaphors which are the 'lexicalized' and 'non-lexicalized' metaphors. A 'lexicalized' metaphor refers to lexical metaphoric unit which in association with a fixed meaning in the lexicon due to its frequent use in specific context. To illustrate, we have the example of the word 'lion' in French and English, 'lion' which is metaphorically associated to a 'brave man'. A 'non-lexicalized' metaphor 
is a metaphor semantic content differs according to the context it is used in (Dickins 2005: 231). For instance, in the utterance 'Il est comme la mer', 'he is like the sea', the semantic content of sea will vary depending on the context.For example, the person that is being decribed can 'as angry as the sea', 'generous as the sea', 'as ambiguous as the sea' or 'as charming and seductive as the sea'.

\subsubsection{Descriptive approach}

Van den Broeck is one of the main proponents of the descriptive approach to metaphor translation. According him, the prescriptive approach does not take into account important factors such as the function of the metaphor. He argues that the most important is to "distinguish between categories, uses and functions of metaphor" (Van den Broeck 1981:74) because the function of metaphor and its mutual relations with other components (context, genre, syntax, etc) influence its translation.Van Den Broeck's metaphor classification is made of three categories according to how they are conventionalized in the source language. His categorization includes: private metaphors which are creative metaphors associated with the writer's personal style, conventional metaphors which are metaphors used within a wide level of a community. The third and last cateogry is that of lexicalized metaphors which are overused metaphor that start to lose their metaphoric aspect and are perceived as lexical items which justifies the name 'lexicalized metaphors'.

Van den Broeck suggests three strategies in translating different types of metaphors:

(1) Translating 'sensu stricto' in case there is a perfect match both in the SL and TL.

(2) Substitution

(3) Paraphrase.

Menachem Dagut, 1976: 28 rejects Newmark's division of metaphors. Instead, he proposes the concepts of metaphor translability and untranslability which were originally challenged by Van de Broeck. Dagut says that the translability or the untranslability of a metaphor depends on how the speakers of a given TL share the cultural experiences and associations drawn by the metaphor. According to Dagut, there are three cases when it comes to metaphor translation:

- Novel translation which, according to him, cannot be translated.

- Ephemeral metaphors which are convensional metaphors that have become empty of their metaphoricity. Dagut consider this type of metaphor translatable.

- New metaphors that start being used through the language speakers and therefore lose their uniqueness.

(See Khadidja 2017) 


\subsubsection{Cognitive approaches of Metaphor Translation}

In one of his papers, Zoltán Kövecses, 2003: 311 is more interested in the cross-cultural comparison of metaphors. This area of researchis also known as the 'applied cognitive linguistics'. Kövecses deals with the contrastive analysis of metaphor in different languages, rather than its actual translation. According to him, the problem lies in conveying in different languages, the same figurative expression. For Kövecses, a metaphoric expression a given source language can have the following eauivalents:

1. The identical expression of the same CM;

2. A non-identical expression of the same $\mathrm{CM}$;

3. A non-identical expression of another $\mathrm{CM}$, with an identical figurative meaning;

4. A non-identical expression of another CM, with another figurative expression;

5. A non-metaphoric expression.

Hiraga, 1991 dealt with the comparison of conceptual metaphors between English and Japanese. From his works in this area, he proposed the following pattern:

1. A similar conceptual metaphor and a similar linguistic metaphor like in TIME IS MONEY.

2.An identical conceptual metaphor and anotherlinguistic metaphor. Here the source and the target languages share the same conceptual metaphor but not the same linguitic metaphors.

3. Different conceptual metaphors, same linguistic metaphor.

4. Different conceptual metaphors and different linguistic metaphors. Different conceptual metaphors and different linguistic metaphors.

Mandelblit, 1995: 483 thinks that the probem encountrerd in metaphor translation "resides in the use of different metaphorical mappings between the SL and the TL to express the same idea". Unlike Hiraga who is focused only on the cultural similarities and differences, Mandelblit, 1995 deals with their implications in translation process. As such, translation is no more just about a trasnfer from one language to the other but a trasfer from one culture to the other as well. According to Mandelblit, 1995, there are two possible hypotheses which are:

(1) $\mathrm{SMC}=$ Similar Mapping Condition: in this hypothesis it is assumed that the linguistic metaphors both in the ST and th TT correspond to the same metaphoric mapping. Mandelblit argues that in this type of situation the translation can be done without any problem.

(2) DMC $=$ Different Mapping Condition: here not only the linguistic metaphors in the source and target languages are different, but also the conceptual metaphors. 
Christina Schäffner's, 2004 metaphor translation solution is an elaborated version of Hiraga's model and Mandelblit's hypotheses. Through her new metaphor translation pattern, she works on both similarities and differences at the conceptual and linguistic levels. Christina's pattern does not focus on the translation process, but rather on the product (product-oriented description vs. process-oriented). In other words, are interest lies on describing and explaining the identified translational solutions. In her description she is not interested in the process of translation, but in the product (product-oriented description vs. process-oriented). That means that her focus is on description and explanation of identified translational solutions. She concludes by saying that metaphor translation cannot be dissociate from translation in general. Schäffner's translation pattern includes:

1.A same conceptual metaphor both in ST and TT at the macro-level;

2. Replacement in TT of structural components of the conceptual schema in the conceptual schema in ST;

3. Further elaboration of the metaphor in the TT;

4. Use of different metaphorical expressions both in ST and TT which can be associated with a more abstract conceptual metaphor;

5. The TT's expression reflects another aspect of the conceptual metaphor .

Schäffner stresses out that there is a need to reconsider classic procedures of translation, and reminds that the five patterns she suggests cannot act as ready-made conceptual metaphors' translation procedures to be taught in translation schools. (Schäffner, 2004: 1267)

\section{Evaluation of the approaches to Metaphor Translation}

In the previous section, approaches to metaphors translation where discussed. They are linguistic and cognitive linguitics approaches. From the discussions made above on the linguistic approach to metaphor translation, we have seen that it is divided into the prescriptive and descriptive approaches and it results that, while the prescriptive approach to the translation of metaphor focuses mainly on the accurate representation of the source text's content, the descriptive approach deals with describing the emperical factors like contextual, cultural and communicative content that are inolved in a metaphor. In addition, the linguistic prescriptive approach consider metaphor as a translation difficulty that can be overcome with the use of prescribed solutions, whereas the linguistic descriptive approach processes by adopting a framework which has no concrete statement on whether a metaphor translatable or untranslatable, nor recommended procedures for metaphor translation. Rather, the issue is discussed in a broader scope which decribes the textual, contextual and communicative dynamics implications for metaphor translation.

According to Gideon Toury, 1995 , the linguistic approaches described above are all source text-oriented. He 
states that looking at metaphor translation from a target text-oriented perspective can enable to get different strategies for dealing with metaphors. He adds two perspectives in the study of metaphor translation: namely source text-oriented and the target text-oriented perspectives. As for the cognitive linguistics approach to metaphor translation, the focus is put on the understanding of the metaphors as a culture-bound phenomenon that varies between cultures. While the linguistic approaches focus on the ST and the TT, the cognitive liguistic approach focuses on the description and explanation of identified translational solutions on one hand, and how SL and TL conceptualize the metaphors. Therefore, the cognitive liguistics approach brings more hints to the translation of metaphors because its aim is to have a minimum loss when translating metaphors. Massey and Ehernsberger-Dow, 2017 state that conceptual metaphor scholars have seldom considered translation. According to Muñoz Martin, 2013 using the process-oriented of conceptual metaphor in translation can be important in providing data and insights to assess the theories and claims of the conceptual metaphor and cognitive linguistics.

\section{Future scopes}

From this research, it is revealed that metaphor can be understood from different angles such as linguistics, pragmatics and cognitive linguistics. However, the translation of metaphor has always been restrain to the above mentionned domains. Translation Studies as an independent discipline do not possess its own strategies for metaphor translation. As stated by Mark Shurttleworth, 2014 in his paper Translation and metaphor studies: Possible paths of interaction between two well-established disciplines, the fact that translation scholars are bilingual and bicultural as well, enables them to provide an excellent source of data regarding interlingual and intercultural variation to counterbalance these universalist tendencies of the conceptual metaphor theories, which still survive in some parts of the discipline. For future researches, scholars of translation should work on making their own theoritical insights and practical findings available to their colleagues of the neighboring fields instead of absorbing their theories and views.

Scholars should work on universal strategies for metaphor translation as the existing theories differ from one area of study to the other, which causes difficulties to student translators and translation teachers on what strategies to adopt when translating metaphorical expressions as a whole, and metaphors in particular. This can happen if scholars from translation engage in working together toward a metaphor translation strategy that will include the various perspectives of metaphor understanding and metaphor translation as well.

Further research shoud also be done in the domain of metaphor studies as it barely does not exist a complete 
theory of metaphor, some see it as purely linguitic, others as embodied to human nature.

\section{Conclusion}

Metaphors are studied within three main schools of thought, that are the semanctic, pragmatic and cognitive schools of metaphors. The semantic approaches of metaphors involve two main views, namely the Comparison View and the Interaction View. While the Comparison View defines metaphor as a substitution of literal language, the Interaction View sees it as a way of interacting. The pragmatic approaches study metaphors from three different angles, the 'Indirect Speech Acts' theory, Grice's theory of 'Conversational implicatures' and the 'Relevance Theory'. The cognitive approach to metaphor also known as the Conceptual Metphor Theory (CMT), sees metaphor as a way of coneceptualizing the language. According to their functions, we can distinguish three category of metaphors namely: structural, ontoligical and orientational. Attempts to explicate metaphor translation effectively starts after Dagut(1976). Metaphor translation is studied from the linguistic (prescriptive and the descriptive approaches) and the cognitive linguistics view. From the different approaches to metaphor translation, it can be noticed that while the prescriptive school of metaphor translation focuses on accurate tranfer of the ST content, the descriptive approach is based on the empirical factors that are involved the metaphor translation. Furthermore, linguistic approaches focus on the ST and the TT, whereas cognitive liguistic approach focuses on the description and explanation of identified translational solutions and how SL and TL conceptualize the metaphors. All strategies are quite complementary and it is for the translator to adapt them depending on the situations he faces.

\section{References}

Aristotle. (1997): Poetics. Trans. S.H. Butcher. Ed. Stanley Applebaum. Toronto: Dover Publications,Inc.

askoxford.com.(2009). Oxford University Press. 20 June 2009. http://www.askoxford.com

Austin, John Langshaw (1975): How to Do Things with Words, 2 nd ed., James Opie Urmson and Marina Sbisà eds., Cambridge: Harvard University Press.

Black, Max. (1955)."Metaphor.” Proceedings of the Aristotelian Society 55: 273-294.

Dagut, Menachem (1976).“Can 'Metaphor’ Be Translated?” Babel, 22:1, pp. 21-33.

Davidson, Donald. "What Metaphors Mean.” On Metaphor. Ed. Sheldon Sacks. Chicago: University of Chicago Press, 1978. 29-46.

Dickins, James (2002). Thinking Arabic Translation, London: Routledge.

Dickins, James (2005). Two models for metaphor translation, Target, 17:2, Amsterdam: John Benjamins Publishing Company, pp. $227-$ 
273.

Grice, H. Paul. (1989). Studies in the Way of Words. Cambridge, MA: Harvard University Press.

Hiraga, M.K. (1991). "Metaphor and comparative cultures", in Fendos, P.G.J. (ed.) Cultural communication: East and west. Taiwan: Tai

Cheng Publishing, pp. 140-166.

Kerbrat-Orecchioni, Catherine (1977). La Connotation. Lyon: Presses Universitaires de Lyon.

Khadidja Merakchi. (2017). The Translation of Metaphors in Popular Science from English into Arabic in the domain of Astronomy and Astrophysics.Dissertation thesis.

Kövecses, Zoltán (2002). Metaphor: A Practical Introduction, New York: Oxford University Press.

Kövecses, Z. (2003). “Language, Figurative Thought, and Cross-Cultural Comparison.” Metaphor and Symbol, 18:4, 311 - 320

Kövecses, Zoltán (2005). Metaphor in Culture: Universality and Variation, Cambridge: Cambridge University Press.

Lakoff, Geroge (1980). “Cocenptual Metaphor in Everyday Language”. The Journal of Philosophy, volume 77, issue 8 (453-456).

Lakoff, Geroge (1987). Women, Fire, and Dangerous Things: What categories reveal about the mind, Chicago: Chicago University Press.

Lakoff, George and Mark Johnson (1980): Metaphors We Live By, Chicago: University of Chicago Press.

Mandelblit Nili (1995). "the Cognitive View of Metaphor and its Implications for

Translation Theory" in Marcel Thelen and Barbara Lewandowska-Tomaszczyk eds.:Translation and Meaning, Part 3,

Hogeschool: Maastricht, pp. 483-495.

Massey, Gary and Maureen Ehrensberger-Dow (2017). Translating Conceptual Metaphor: The Processes of Managing Interlingual

Asymmetry, Research in Languag, vol. 15:2.

Muñoz Martín, Ricardo. 2013. More Than a Way With Words: The Interface Between Cognitive Iinguistics and Cognitive Translatology.

In Ana Rojo and Iraide Ibarretxe Antuñano (eds.), Cognitive Linguistics and Translation, 75-94. Berlin: Mouton de Gruyter.

Newmark, Peter (1980).“The Translation of Metaphor”, Babel, 26:2, pp.93-100.

Newmark, Peter (1982). "The Translation of Authoritative Statements” META, 27:4, pp.375- 391.

Newmark, Peter (1985). "The translation of metaphor" in Wolf Paprotté and René Dirven eds.: The Ubiquity of Metaphor, Amsterdam and Philadelphia: John Benjamins, pp. 295-326.

Newmark, Peter (1988a). a Textbook of Translation, Hemel Hempstead: Prentice Hall

International Ltd.

Newmark, Peter (1988b). "Pragmatic translation and literalism”, in TTR (Traduction,

Terminologie, Redaction), 1:2, pp. 133-145.

Newmark, Peter (2004). “Translation Now-27”, The linguist: Journal of the Institute of Linguists, 43:4, pp. 127-129.

Richards, I.A. (1936). The Philosophy of Rhetoric, Oxford: Oxford University Press.

Richards, I.A.(1965). The Philosophy of Rhetoric. New York: Oxford University Press.

Schäffner Christina (2004) . "Metaphor and translation: some implications of a cognitive approach" Journal of Pragmatics, 36:7, pp. 1253-1269.

Searle, J. "Metaphor." Metaphor and Thought. Ed. A. Ortony. Cambridge: Cambridge

University Press, 1979. 92-123.

Shakespeare, William (2003). Romeo and Juliet. Ed. Dympna Callaghan. Boston: Bedford/St. Martin's.

Shuttleworth, Mark. 2014. Translation Studies and Metaphor Studies: Possible Paths of Interaction Between Two Well-Established Disciplines. In Donna R. Miller and Enrico Monti (eds.), Tradurre Figure/Translating Figurative Language, 53-65. Bologna: Bononia University Press.

Sperber, Dan and Deirdre Wilson. Relevance: Communication and Cognition. Oxford: Blackwell, 1986.

Toury, Gideon (1995). Descriptive Translation Studies and Beyond, 
Amsterdam: Benjamins.

Van den Broeck Raymond (1981). “The Limits of Translatability Exemplified by Metaphor Translation” Poetics Today, 2:4, pp. $73-87$. 